\title{
Does long-term focus increase victim- blaming? A study on the just-world hypothesis using the modified Stroop task
}

KOMÁROMY ZSUZSA ${ }^{1}$

JÁNOS RÉKA ${ }^{2}$

\begin{abstract}
According to the just-world hypothesis (Lerner, 1980), people have an inherent need to believe that the world is a just place, where people generally get wh t they deserve. One of the benefits of holding this conviction is that it can promote investing in long-term goals. Acts of secondary victimization, such as blaming or derogating the victim can also be explained by just-world beliefs. This study looked at the effect of perceiving an innocent victim (a supposed threat to the belief in a just world) and long-term focus on the activation of the justice motive. We measured participants' reaction times for justice-related and other stimuli with the help of the modified Stroop task ( $N=66)$. A significant difference between justice-related and neutral words has been found after being confronted with the threat to the belief in a just world, indicating that it indeed activated participants' justice motive. Long-term focus did not have any significant effect. Higher levels of belief in a random world have been associated with greater victim-blaming tendencies.
\end{abstract}

\section{Keywords}

justice motive, belief in a just world, emotional Stroop, victim-blaming, victim derogation, long-term focus

\footnotetext{
${ }^{1}$ Babes-Bolyai University, Faculty of Psychology and Educational Sciences, E-mail: zsuzsakomaromy@gmail.com, Tel: 0755380441

${ }^{2}$ Babes-Bolyai University, Faculty of Psychology and Educational Sciences, Department of Applied Psychology,E-mail: reka.janos@ubbcluj.ro
} 